11th International Conference on Industrial Engineering and Operations Management 21St Conference on Industrial Engineering

Valencia, Spain, July 5-6, 2017

\title{
Limitations and pitfalls of the brain that prevent us from thinking
}

\author{
Portela $\mathbf{J}^{1}$, Rodríguez-Monroy $\mathbf{C}^{2}$
}

\begin{abstract}
When we think or make decisions, we must not forget that there are several internal "pitfalls" that cause our brain to make decisions incorrectly. Many authors have written on various pitfalls that may affect us. In this paper, five of them are identified and they are: The use of patterns when thinking, the relativity of things, the anchor effect, loss aversion, value attribution and diagnosis bias.
\end{abstract}

Keywords: Thought, brain, patterns, business innovation

\footnotetext{
${ }^{1}$ José Luis Portela (e-mail address: jlportela@ faculty.ie.edu) Operations Department IE Business School. Calle María de Molina 11

${ }^{2}$ Carlos Rodríguez-Monroy ( $₫$ e-mail: crmonroy@etsii.upm.es)

Technical University of Madrid. Higher Technical School of Industrial Engineers of Madrid. C/ José Gutiérrez Abascal 2, 28006 Madrid
} 


\section{Introduction}

Everyday knowledge, theories and procedures are being discovered and shared by people and organizations. The key, therefore, is not usually knowledge. The key lies in how managers make decisions: in other words, how these managers are able to think in a different way. This research work focuses on identifying the "limitations and pitfalls", both external and internal, which influence us to think and make decisions.

It is a well-known fact that the brain makes certain errors in decision making. While it is true that it is a known fact that decisions are made by the unconscious brain, to date little is known about exactly how it does this. And while it is true that we cannot know for certain how it does this, it is also true that, if these errors are repetitive, we can establish a cause-and-effect relationship and that is what it is all about. The key is to recognize that when we are irrational, we are predictably irrational, which would lead to thinking that our irrationality always occurs in the same way and, therefore, we should identify these behavioral patterns.

\section{Use of Patterns}

The way in which the brain works is by connecting neurons. A single neuron can create between 10,000 and 15,000 connections.

If the entire brain has an average of 100,000 million neurons, the average number of synapses in a human brain is a total of: one trillion synapses $(100,000$ million neurons average times 10,000 connections), a one followed by 15 zeros.

The first-time connection of neurons through synapses consumes more energy than the use of these connections once they have been connected. Thus, for a baby, energy consumption by the brain reaches $60 \%$ of the total energy instead of $20 \%$, which occurs in adults. This is due to the fact that it is specifically during these early stages that the bulk of new connections in the brain is being formed. 
Neurologist Marcus Raichle E. published an article in Science (2006) called 'The Brain's Dark Energy'. "It is a complex problem," says, Pascual-Leone "allow me to give you some figures to give you an idea of magnitude of the issue. The brain is approximately $2 \%$ of the weight of the human body. However, it consumes $20 \%$ of the energy of the human body.

Making a decision requires some calculations. The brain is always trying to save the maximum amount of energy. The way it does this is through the establishment of objectives, the restriction of communications and the creation of models that it uses to "pattern" behaviors and facts.

The brain has to make approximately 4000 decisions per day. The best way to do it, using the lowest possible energy consumption, is to use synapses which are already established instead of having to create new ones from scratch.

What does this mean?

According to Edward de Bono the mind creates patterns, because, once created, they can be reused in the process of new thoughts and there is no need to be creating new connections from scratch.

The dominant ideas prevent us from creating new situations as they mark the journey of our thoughts and as a result we always think in a similar way.

What happens is that when something different from what was experienced reaches the brain for the first time, the first thing it does is to see if it fits into some of the patterns it has. If an adult, who played with cars as a child, picks up an iPad for the first time and drops it, their brain knows perfectly what the outcome will be, because as a child when they dropped the car, it fell. What the brain does here is to relate that object with other previous ones and says "the iPad is the same as the little cars you had as a child"

The first thing that the brain does, therefore, is to see whether things of the past are similar to assign one to it. Once we have this list of ideas of the past, we select the one we deem best. In other words, we do not think, we simply bring thoughts from the past to be used in the present.

\section{The relativity of things}

Dan Ariely, in his book "Predictably Irrational" speaks of the way in which the brain is able to compare things. As Ariely indicates "the brain is not able to assign an absolute value to an object unless it compares it with another" 
As a result, we humans rarely choose things in absolute terms. We do not have a meter of internal value that tell us how much things value. To be able to give a value to something, we have to look at the advantages or disadvantages of one thing in relation to another, and in this way we will be able to estimate its value.

The example that Dan Ariely in his book "Predictably Irrational" reflects this situation.

On the website www.economist.com there were three subscription options. The options were as follows:

1) Subscription to the on-line access for only $\$ 59$.

2) A subscription to the printed version for only $\$ 125$.

3) Subscription to on-line access and printed version for $\$ 125$.

In the case, he explains, $84 \%$ chose option 3 . Why is this? In choosing the best option, the brain tries to use the minimum amount of energy, or, to put it another way, it tries to think as little as possible. Of the three options, comparing the first and the third, or the first and last is much more complicated than comparing the second and the third, since these are much closer and in addition there is the fact that one is clearly better than the other.

\section{The anchor effect}

The naturalist Konrad Lorenz discovered that the gosling (offspring of goose), upon hatching from the egg, sticks to the first moving object that it finds, which naturally tends to be its mother.

Lorenz discovered it in one of his experiments, because he was the first thing the young geese saw and since that moment they have followed him loyally everywhere.

What Lorenz demonstrated is that the goslings' initial decisions not only make decisions based on what is available in the environment, but stick to their decision once it is made. Lorenz called this natural phenomenon "imprinting".

Does our brain act the same as that of these goslings? Could our first impressions and data also produce an imprint? This phenomenon is known in behavioral economics as an "anchor".

This happens when we observe an object that we had never seen before for the first time and our brain "anchors" the first price that we see and thus, almost magically, is linked to it, conditioning future prices of the product to this first observed price.

Drazen Prelec, Professor of MIT's Sloan Management School, did an experiment to explain the phenomenon of locking in prices. He pulled out a bottle Cotes du Rhone Jaboulet Parallel of 1998.

In the class, there were 55 students. That day Drazen George Loewenstein and Dan Ariley made a request of the students. They were asked to record the last two 
digits of their social security numbers on a piece of paper. What he was trying to show is what is called "arbitrary coherence".

The idea was to demonstrate that the best of having an arbitrary number in one's head would create an anchor in the head that would determine what the students would be willing to pay.

Drazen grabbed another bottle, a Hermitage Jaboulet La Chapelle of 1996 with a ranking of 92 points in Wine Advocate magazine. The previous bottle that we had talked about had a score of 86 .

There were also four articles, a wireless trackball (Logitech TrackMan Marble FX), a Wireless Keyboard and Mouse set, (Logitech iTouch), a design book (the perfect package: how to increase value by using graphic design) and a box of half a kilo of Belgian chocolates from Neuhaus

Forms were distributed where all the articles appeared. Then, next to each article, they were to write the last two digits of their social security numbers, for example 23, and indicate that this would be the price in dollars of the article.

Then, they simply have to say whether or not they would buy the item for that price.

In addition to this there was another box in which they were to enter the maximum amount they would pay for each of these items. This would be like a bid in an auction for each article. Once they received all articles, the winner was given the article once the amount had been paid.

The question is thinking about whether the social security number influenced, or not, the form in which each one of the students answered.

After analyzing the data, the conclusions were devastating. Students with higher digits (80 to 99) were the ones that made higher bids, while those who had lower digits ( 1 to 20 ) were the ones that made lower bids

The top quintile, for example, pushing an average of $\$ 56$ for the wireless keyboard, while the bottom quintile had bid only an average of $\$ 16$.

At the end, students whose social security numbers were in the top quintile made bids that were between $216 \%$ and $346 \%$ higher than those of students whose last two digits of the social security were in the bottom quintile.

The data showed that the relative prices between the various products, comparing them was logical. They paid more for the best wine than for the worst, for example.

What is significant is that once the students were willing to pay a certain price for a product, their willingness to pay for other articles in the same category happened to be in related with the first price, the anchor. This is termed "arbitrary coherence".

The anchor effect was also mentioned by Daniel Kahneman, who won the Nobel in economic science, in his book "thinking fast and slow". In one experiment, experienced German Judges were inclined to give a shoplifter a longer sentence if they had just rolled a pair of dice loaded to give a high number. 


\section{5 loss aversion, value assignment and diagnostic bias}

In the book "the irrational impulse" of Ori Brafman and Rom Brafman about the effect of loss and how it affected both the time of making decisions, but also speaks to us of how loss aversion affects us when making decisions

The best way to explain it is to start with an example that he narrates in his very informative book.

Macarthur Job and Matthew Tesch described the chain of events that led to the air collision of Tenerife in Air Disasters: Volume 1, Aerospace Publications, Sydney, Australia, 1994, pp. 165-180.

The KLM Flight 4805 was a Jumbo 747 to the path that Amsterdam airport of Las Palmas in the Canary Islands.

The flight was quiet and received an urgent message from international air traffic control. A terrorist bomb had exploded in the flower shop of the airport and so the airport was closed. It was noted that it had to land at the Tenerife airport.

When the plane landed, Jacob realized that if he was there for a very long time, he would have to pass through the compulsory rest period, so that they could take off later than half past six in the evening.

Two hours after it occurred to him to refuel in order to gain time and the news that Las Palmas had finally opened, came but it was already too late to stop the process of refuelling, which lasted for 35 minutes. But this was not all, suddenly a dense layer of fog began to descend on the track, after which Van Zanten realized that if he continued staying there, he could not take off.

In those moments, what then seems like something out of an abnormal situation, he accelerated the engines and headed toward the track.

"Wait a moment, said of Van Zanten co-driver bewildered. We do not have authorization for takeoff

I know," replied the commander while brakeing- Come on, ask for it."

The co-pilot turned on the radio and received the permission to fly- the adoption of the flight plan, but the tower did not say anything about the criucial authorization take-off

However, Van Zanten turn the throttles to full power and began to take off, with the fatality of crossing a Pan Am 747 in middle of the track, crashing into it. A total of 584 people lost their lives.

How was it possible that Van Zanten has been trying to get off the ground without flight authorization?

Our behavior and decision-making is influenced by a set of underlying psychological flows much more powerful and penetrating than most think

What were the internal hidden forces that influenced this decision?

- Loss aversion. Our tendency to do everything possible to avoid potential losses. We experience pain associated with a loss much more vividly than the joy of getting a profit. 
- Value attribution: Our inclination to imbue a person or thing with certain qualities based on the initial perception of its value and not on objective data.

- Diagnostic bias: Our blindness to all evidence that contradicts our initial assessment of a person or situation

If we go back to the air accident, we realize the error that the pilot committed who talked with the commander who had no authorization to fly. The fact of attributing a supposed value of always being right, not just because one is the commander but to because one is the best commander of KLM, attached to the diagnosis bias that made the brain hide very clear and accurate information that they had no authorization to fly, it turned out that the pilot did nothing to stop the plane, despite being an obligation.

\section{Conclusions}

As we have seen there are many "pitfalls" into which our brain can fall when making a decision. The key is to get to know them in advance for when we are thinking to not fall into any of them.

We should avoid using learned patterns whenever we are thinking. To do this we must check if the premises from which they originate, are learned or reasoned. Another way to avoid falling into learned patterns, is to erase them although these seem necessary for the decision. In other words, we must check our patterns, to be sure that they are true or valid in the current context.

When we are comparing between several options and we have chosen one, we need to review them again to reflect on whether we have eliminated some of them simply by the fact that it is not comparable with anything.

To avoid the anchoring effect, we have to try to eliminate all potential anchors that we have about the object that we are thinking about. That is to say, if we thought that something had a certain value, we should reflect on whether this value is true or it is just there because of the anchoring effect.

Finally, when we have made a decision, we have to check whether we have made it because of the fear of the losing something. At the same time, we should also check whether we have attached some value to someone and we have believed what he or she has said, without even questioning it.

In summary, to be sure that the choices we make are correct, we should systematically check all these aspects to be sure that we have not fallen in any of the 'pitfalls' of our brain 


\section{References}

Ariely D (2008) las trampas del deseo. Ariel.

Daniel Kahneman. (2001). Thinking fast and slow. Farrar, Straus and Giroux.

De Bono, Edward (1986) Lateral Thinking: A Textbook of Creativity Pelican books.

De Bono, Edward. (1992) Parallel Thinking. From Socrates to De Bono. The pengium group.

De Bono, Edward. (1994) Creative Thinking. Power of Lateral Thinking for the Creation of New Ideas. McQuaig Group, Inc.

The companion in the bird's world: J. für Ornithologie 83 (2-3), p. 137 - 215 y p. 289 - 413 (reprint 1965, in: "Human and Animal Behavuiour" Vol. 1). (1935).

Marcus E. Raichle Published in Science (2006), The Brain's Dark Energy. N.p., 2017. Print.

Macarthur Job y Matthew Tesch Air Disasters: (1994) Volume 1, Aerospace Publications, Fyshwick, Australia, pags 165-180.

Ori Brafman y Rom Brafman (2009) Irrational Impulse, SLU. Espasa Libros. 